\title{
Análise dos Níveis de Empatia de Professores e Preceptores Médicos de um Curso de Medicina
}

\author{
Analysis of Empathy Levels of Teachers and Medical Preceptors \\ of a Medical Course
}

\author{
Geórgia Ferreira Nunes ${ }^{I}$ (iD \\ Thays Ferreira Guimarães ${ }^{I}$ iD \\ Júlia da Paixão Oliveira Mello e Pargeon ${ }^{I}$ (D) \\ Gabriela Cunha Fialho Cantarelli Bastos ${ }^{I}(\mathbb{D}$ \\ Antonio Márcio Teodoro Cordeiro Silva ${ }^{I}($ D \\ Rogério José de Almeida ${ }^{I}$ (iD
}

PALAVRAS-CHAVE

- Docentes de Medicina.

- Educação Médica.

- Empatia.

Introdução: O objetivo deste estudo foi avaliar os níveis de empatia, bem como os aspectos sociodemográficos e pessoais relacionados a docentes e preceptores médicos de um curso de Medicina. Métodos: Trata-se de um estudo transversal analítico com abordagem quantitativa. A pesquisa foi realizada por meio de questionários aplicados a docentes e preceptores médicos vinculados ao curso de Medicina da Pontifícia Universidade Católica de Goiás (PUC Goiás), desde o módulo I até o XII, os quais tinham contato direto com os acadêmicos, assim como com os pacientes. A amostragem utilizada foi por conveniência. A coleta de dados foi realizada entre os meses de agosto e novembro de 2018. Dois questionários foram aplicados, sendo um com dados sociodemográficos e o outro com a Escala Multidimensional de Reatividade Interpessoal (EMRI), que mensura multidimensionalmente a empatia. Resultados: Incluíram-se na pesquisa 101 médicos, entre docentes e preceptores. A média de idade foi de 45,2 $( \pm 8,4)$ anos. Quanto ao sexo, $45,5 \%$ da amostra foi composta pelo sexo feminino e $54,4 \%$ pelo sexo masculino. A maioria era casada (80,2\%) e possuía alguma religião. Identificaram-se maiores escores de empatia no gênero feminino, nas dimensões FS $(p=0,0468), C E(p=0,0219)$ e AP $(p=0,0230)$, bem como na média geral $(p=0,0057)$. Níveis maiores de empatia também foram identificados entre os que possuíam uma religião, na dimensão AP $(p=0,0074)$. Os aspectos pessoais que obtiveram maiores escores nas dimensões da escala foram docentes e preceptores médicos que afirmaram que procuram orientar os seus alunos sobre empatia, dimensões FS ( $p=0,0341), C E(p=0,0398), T P(p=0,0464)$ e média geral $(p=0,0442)$; aqueles que afirmaram que são pessoas empáticas, dimensões FS ( $p=0,0327), C E(p=0,0061), T P(p=0,0008)$ e média geral ( $p=0,0067)$; aqueles que estão satisfeitos com suas atitudes no exercício da docência, dimensão TP ( $p=$ 0,0289). Conclusão: Os dados apontaram que aspectos sociodemográficos e pessoais dos docentes e preceptores médicos exercem influência direta em maiores ou menores níveis de empatia. Tal evidência é relevante, já que a formação de futuros médicos mais empáticos depende da influência desses docentes e preceptores médicos. 


\section{KEYWORDS}

- Faculty Medical.

- Medical Education.

- Empathy.

\section{ABSTRACT}

Introduction: To assess the level of empathy, as well as sociodemographic and personal aspects related to teachers/ preceptors of a medical graduation course, who are also clinicians. Methods: This is a cross-sectional analytical study with a quantitative approach. The research was carried out through questionnaires applied to teachers and medical preceptors linked to the medical course of the Pontifical Catholic University of Goiás (PUC Goiás), from module I to module XII, who had direct contact with the students, as well as with patients. The data collection period ranged from August to November 2018 and was developed by means of a convenience sampling. Two different questionnaires were applied, the first one being about sociodemographic and personal aspects, and the second one the Interpersonal Reactivity Index (IRI), which multidimensionally measures empathy. Results: The participants included 101 doctors who are teachers and/or preceptors in a medical graduation course. The mean age was 45.2 ( \pm 8.4 ) years old. As for gender, $45.5 \%$ of the sample consisted of women, and $54.4 \%$ of men. Most participants are married (80.2\%) and declared having a religion. This research showed higher scores of empathy in the female gender in Fantasy (FS) ( $p=0.0468)$, Empathic Concern (EC) $(p=0.0219)$ and Personal Distress (PD) ( $p=0.0230)$ dimensions, as well as in general average $(p=0.0057)$. Higher levels of empathy were also identified in those participants with a religion, in the PD dimension $(p=0.0074)$. The personal aspects that most influenced the empathy levels were: teachers/preceptors that cared about stimulating their students regarding empathy in the FS ( $p=0.0341), E C(p=0.0398)$, Perspective Taking $(P T)(p=0.0464)$ dimensions and general average ( $p=0.0442)$; those who affirmed to be empathetic themselves $-F S(p=0.0327), E C(p=0.0061), P T(p=0.0008)$ dimensions and general average ( $p=0.0067)$; and those who are satisfied about their teaching practice - PT dimension ( $p=0.0289$ ). Conclusion: The collected data showed that sociodemographic and personal aspects have a direct influence on empathy levels. Such evidence is relevant since the education of medical students suffer the influence of the teachers/preceptors' approach and behavior.

Recebido em 21/11/19

Aceito em 15/12/19

\section{INTRODUÇÃO}

Existem diversas formas de conceituar empatia. $O$ conceito mais antigo de empatia caracteriza-se como a habilidade de identificar o que está na consciência de outra pessoa ${ }^{1}$. O conceito atualmente mais conhecido foi desenvolvido na década de 1960 pelo psicólogo norteamericano Carl Rogers, que define empatia como sendo a habilidade, aprendida ou desenvolvida, de realizar vínculo afetivo e cognitivo, de penetrar no mundo perceptual do outro e acompanhar suas mudanças, medos e outros sentimentos, transmitir a maneira como sente o mundo do outro, movendo-se delicadamente entre o mundo do outro e o próprio ${ }^{1}$.

$\mathrm{Na}$ área da saúde, a empatia é definida como um atributo predominantemente cognitivo e não apenas emocional, que engloba a capacidade de entender as experiências, inquietudes e perspectivas do paciente, além da capacidade de comunicar esse entendimento ${ }^{2}$. Outro estudo leva o supramencionado conceito a outro nível, definindo empatia não apenas como uma capacidade cognitivo-emocional, mas como uma complexa interação de processos emocionais, cognitivos e comportamentais ${ }^{3}$. Esse segundo conceito leva em consideração fatores socioculturais nos processos de tomadas de decisão na prática médica. $\mathrm{O}$ estudo enfatiza que o foco nos fatores socioculturais, sobretudo na educação médica, encoraja a consideração de aspectos psicodinâmicos, psicológicos e psicanalíticos no espectro da empatia ${ }^{3}$.

Tempos atrás, o médico era um profissional voltado exclusivamente para o problema biológico do paciente, com pouca ou nenhuma preocupação com aspectos psicossociais. À medida que a humanização da profissão passou a ser uma prioridade, dando importância às questões psicossociais, o médico passou a se colocar no lugar do outro fazendo com que o encontro clínico se tornasse mais efetivo em uma perspectiva biopsicossocial ${ }^{4}$.

Nos dias de hoje, é inconcebível que um médico atenda um paciente sem se conectar com ele. Quando não há a conexão médico-paciente, o paciente sente-se, em geral, tratado incompletamente. Mas, no âmbito da formação médica, seria possível desenvolver a empatia nos acadêmicos de Medicina? Quais aspectos dos médicos que são docentes e/ou preceptores estariam relacionados com uma maior empatia?

$\mathrm{Na}$ atualidade, essas perguntas devem ser consideradas no âmbito da educação médica. Para tanto, é possível se valer de instrumentos de pesquisa científica que possuem a capacidade psicométrica e fidedigna de mensurar os níveis de empatia de um indivíduo, bem como de investigar os aspectos associados a maiores ou menores escores de empatia. No presente estudo optou-se por utilizar a Escala Multidimensional de Reatividade Interpessoal (EMRI), que procura mensurar a empatia de uma forma mais abrangente, por meio de experiências emocionais, cognitivas e sociais a que o indivíduo está submetido na sua vida em sociedade ${ }^{5}$. Essa escala avalia quatro dimensões da empatia, denominadas de angústia pessoal (AP), consideração empática (CE), tomada de perspectiva (TP) e fantasia (FS) ${ }^{5}$.

O Ministério da Educação, por meio das Diretrizes Curriculares Nacionais do Curso de Graduação em Medicina, preconiza uma formação médica voltada para um olhar biopsicossocial, o qual demanda sobremaneira o exercício da empatia ${ }^{6}$. Sendo assim, infere-se que o docente e/ou preceptor médico deve ter duas raízes: dominar o conteúdo da disciplina que ensina e saber ensinar aquilo que domina, e esse saber deve envolver postura participativa em todo o processo ensino-aprendizagem ${ }^{7}$. Somando a docência na Medicina com a necessidade de formar médicos

REVISTA BRASILEIRA DE EDUCAÇÃO MÉDICA

2 44 (1) : e043; 2020 
com empatia, verifica-se que a tarefa do professor na área médica se torna agora um desafio maior do que outrora.

É fato que a conduta holística e empática que se vive em ambiente familiar tem um papel positivo muito importante no desenvolvimento da socialização e empatia nos integrantes de uma família ${ }^{2}$. No contexto da empatia médica, sabe-se que o ambiente educacional não se restringe apenas ao âmbito universitário, clínico ou hospitalar e que a empatia é crucial para que o ambiente de ensino-aprendizagem cumpra o seu propósito ${ }^{2}$.

É sabido que os docentes e preceptores médicos são fortes influenciadores, bem como referenciais, para seus alunos. Se sua prática pedagógica for baseada na humanização e na empatia, poderá haver um impacto maior na formação de opinião e, consequentemente, na conduta dos acadêmicos. A autoridade sobre o que se ensina é inquestionável quando aquilo se torna visível. É clara a inferência de que a empatia na relação médico-paciente também é docente-dependente. A empatia pode ser estimulada ou facilitada, o que não é possível sem o exemplo do próprio docente ${ }^{8}$.

Caberia ao docente oferecer aos acadêmicos experiências que levem ao autoconhecimento, ao poder de escuta, ao respeito e à tolerância, de modo que eles sejam aptos a identificar suas próprias fraquezas, seus medos e preconceitos. Como empecilhos ao ensino e à prática da empatia pelo docente, podem-se mencionar a grande variedade de professores/preceptores que os acadêmicos têm ao longo do curso e o chamado "endurecimento" dos acadêmicos de Medicina durante o período de graduação .

Assim, o presente estudo teve por objetivo avaliar os níveis de empatia, bem como os aspectos sociodemográficos e pessoais relacionados a docentes e preceptores médicos de um curso de Medicina.

\section{MÉTODOS}

Trata-se de um estudo transversal analítico com abordagem quantitativa. Consistiu em uma investigação que visou estimar qual é a frequência em que determinado evento se manifesta em uma situação específica e do desfecho em estudo, podendo-se ainda verificar se há correlação entre o fator de risco e o desfecho em questão?.

Constitui um método de pesquisa que investiga causa e efeito simultaneamente ou em um curto intervalo de tempo. Tem como características essenciais as seguintes etapas: 1 . a definição da população a ser estudada, 2. o estudo dessa população por meio de amostragem ou de censo 3. a determinação da presença ou não do desfecho e da exposição para cada um dos indivíduos estudados ${ }^{10}$.

A pesquisa foi realizada por meio de questionários aplicados a docentes e preceptores médicos vinculados ao curso de Medicina da Pontifícia Universidade Católica de Goiás (PUC Goiás), desde o módulo I até o XII, os quais tinham contato direto com os acadêmicos, assim como com os pacientes. Como critérios de inclusão, foram entrevistados docentes e preceptores médicos de todos os módulos do curso que estavam envolvidos na parte prática. Não foram entrevistados os docentes e preceptores que não estavam concomitantemente em contato com acadêmicos e pacientes, os preceptores vinculados ao internato rural e aqueles que estavam de licença, não exercendo regularmente suas atividades no curso de Medicina. No período de coleta de dados, havia 210 professores e preceptores médicos elegíveis dentro dos critérios de inclusão e exclusão. A aplicação dos questionários ocorreu entre os meses de agosto e novembro de 2018. A amostragem utilizada foi por conveniência, perfazendo uma amostra final de $101(48,1 \%)$ professores e preceptores médicos.

Para o desenvolvimento da pesquisa, foram utilizados dois instrumentos. O primeiro foi elaborado e construído pelos pesquisadores, composto por variáveis de interesse do fenômeno investigado. Tais variáveis foram: idade, sexo, etnia, estado civil, envolvimento religioso autorreferido, prática de atividade física, há quanto tempo está graduado, há quanto tempo exerce a profissão de docente do curso de Medicina, se foi orientado sobre empatia em algum momento de sua carreira ou formação, entre outras.

O segundo instrumento foi a EMRI que mensura multidimensionalmente a empatia e busca avaliar experiências afetivas e cognitivas da pessoa, podendo ser utilizada para qualificar relações emocionais e sociais ${ }^{5}$. Foi desenvolvida por Davis, no ano de 1983, em sua versão original, sendo adaptada e já validada no Brasil ${ }^{11}$. Tem por objetivo avaliar de forma global o nível de empatia da pessoa em estudo. A EMRI foi criada para avaliar quatro grandes dimensões: $\mathrm{AP}, \mathrm{CE}, \mathrm{TP}$ e FS. A AP refere-se às sensações de desconforto relacionadas ao self, quando o indivíduo imagina outrem em situação de sofrimento, podendo gerar um comportamento de afastamento. A CE está relacionada aos sentimentos gerados pelo sofrimento do outro e à motivação para ajudar as pessoas que precisem. A TP afere a capacidade cognitiva do indivíduo de se colocar no lugar do outro, inferindo e reconhecendo o que o outro sente e pensa. A FS avalia a capacidade de o sujeito transpor-se em seu imaginário, assumindo o papel de um personagem fictício ${ }^{5}$.

O instrumento é composto por 26 sentenças, as quais são distribuídas entre as quatro dimensões a serem analisadas, de modo que AP e TP possuem seis sentenças cada, e CE e FS contêm sete sentenças cada. Todas as sentenças são avaliadas por escalas do tipo Likert, que variam de 1 ("não me descreve bem") a 5 ("descreve-me muito bem"). A soma dos escores referentes a cada sentença é utilizada para calcular o nível global de empatia, e quanto maior o escore, mais alto é o nível de empatia. O escore global de empatia varia de 26 a $130^{12}$.

Com os dados coletados, foi confeccionado um banco de dados utilizando o software IBM SPSS Statistics 18. Posteriormente, realizou-se estatística descritiva com o cálculo da média e do desvio padrão e o cálculo das frequências absoluta e relativa percentual para as variáveis discretas.

Na sequência, aplicou-se o teste de normalidade (Kolmogorov-Smirnov) para distinguir as distribuições paramétricas e não paramétricas, com o intuito de comparar os resultados do questionário estratificado pelas variáveis sociodemográficas. Utilizaram-se, para as distribuições paramétricas, os testes $t$ de Student e a ANOVA, e, para as distribuições não paramétricas, os testes Mann-Whitney e Kruskal-Wallis. Para todos os testes comparativos, foi assumido p-valor menor ou igual a 0,05 como significativo.

Em consonância com a Resolução no 466/2012, antes da aplicação dos questionários, os participantes foram devidamente orientados em relação às questões éticas do estudo e assinaram o Termo de Consentimento Livre e Esclarecido (TCLE). A pesquisa foi registrada na Plataforma Brasil e aprovada pelo Comitê de Ética em Pesquisa da PUC Goiás, com o Parecer nº 2.723.361.

\section{RESULTADOS}

Nesta pesquisa, foram entrevistados 101 médicos, sendo docentes e preceptores de um curso de Medicina. A média de idade foi de 45,2 $( \pm 8,4)$ anos, sendo a menor idade identificada de 27 anos e a maior de 63 anos.

REVISTA BRASILEIRA DE EDUCAÇ̃̃o MÉDICA

3 44 (1) : e043; 2020 
Quanto ao sexo, $45,5 \%$ da amostra foi composta pelo sexo feminino e $54,4 \%$ pelo sexo masculino. O estado civil casado representou uma amostra significativa $(80,2 \%)$, bem como a filiação dos entrevistados a algum tipo de religião $(94,1 \%)$. Nota-se ainda que a maioria dos docentes entrevistados possuía mais de dez anos de graduação, constituindo $88,1 \%$. Em contrapartida, foi refletido que a maioria dos docentes $(53,5 \%)$ atuava como professor de graduação havia menos de dez anos (Tabela 1).

No que se refere aos aspectos pessoais quanto à empatia, $58,4 \%$ dos docentes avaliados afirmaram que obtiveram algum grau de orientação sobre empatia ao longo de sua graduação. Houve um predomínio de $79,2 \%$ que afirmaram buscar dar continuidade à orientação de empatia aos seus alunos. Uma grande maioria $(92,1 \%)$ considerou-se uma pessoa

\begin{tabular}{|c|c|c|}
\hline \multicolumn{3}{|c|}{$\begin{array}{l}\text { Perfil sociodemográfico dos } 101 \text { professores e preceptores médicos } \\
\text { de um curso de Medicina, Goiânia, Goiás, Brasil, } 2018\end{array}$} \\
\hline Variáveis $(n=101)$ & $\mathbf{n}$ & $f(\%)$ \\
\hline \multicolumn{3}{|l|}{ Idade } \\
\hline Até 45 anos & 52 & 51,5 \\
\hline Acima de 45 anos & 44 & 43,6 \\
\hline Não respondeu & 5 & 5,0 \\
\hline Média (DP) & 45,2 & 8,4 \\
\hline Mín. - Máx. & 27 & 63 \\
\hline \multicolumn{3}{|l|}{ Sexo } \\
\hline Feminino & 46 & 45,5 \\
\hline Masculino & 55 & 54,5 \\
\hline \multicolumn{3}{|l|}{ Estado civil } \\
\hline Solteiro & 8 & 7,9 \\
\hline Casado & 81 & 80,2 \\
\hline Divorciado & 12 & 11,9 \\
\hline \multicolumn{3}{|l|}{ Religião } \\
\hline Sim & 95 & 94,1 \\
\hline Não & 6 & 5,9 \\
\hline \multicolumn{3}{|l|}{ Envolvimento religioso } \\
\hline Fraco & 15 & 14,9 \\
\hline Moderado & 50 & 49,5 \\
\hline Forte & 30 & 29,7 \\
\hline \multicolumn{3}{|l|}{ Pratica atividade física } \\
\hline Sim & 75 & 74,3 \\
\hline Não & 26 & 25,7 \\
\hline \multicolumn{3}{|c|}{ Tempo de graduação em Medicina } \\
\hline Menos de dez anos & 12 & 11,9 \\
\hline Mais de dez anos & 89 & 88,1 \\
\hline \multicolumn{3}{|c|}{ Tempo de docência em Medicina } \\
\hline Menos de dez anos & 54 & 53,5 \\
\hline Mais de dez anos & 47 & 46,5 \\
\hline
\end{tabular}

Fonte: Elaborada pelos autores. empática. Quando questionados se a teoria seria suficiente para o desenvolvimento da empatia, 93,1\% afirmaram fidedignamente que não. Dos entrevistados, $99 \%$ enfatizaram que a prática da empatia tem impacto positivo no desenvolvimento e na formação dos acadêmicos de Medicina. Um total de $98 \%$ considerou que a empatia pode, sim, ser desenvolvida nos estudantes. Finalmente, $86,1 \%$ consideram-se satisfeitos, atualmente, com suas atitudes e posturas como docentes e/ou preceptores de um curso de Medicina (Tabela 2).

$\mathrm{Na}$ comparação do perfil sociodemográfico com os escores das dimensões e da média global de empatia medidos pela EMRI, identificouse, com significância estatística, que o sexo feminino em comparação com o masculino apresentou maiores escores nas dimensões FS $(0,0468)$, CE $(0,0219)$ e AP $(0,0230)$, bem como na média geral $(0,0057)$. Aqueles que referiram ter uma religião também apresentaram maior escore na dimensão AP $(0,0074)$ (Tabela 3).

No que se refere à comparação dos aspectos pessoais quanto à empatia com os escores das dimensões e da média global de empatia medidos pela EMRI, identificou-se, com significância estatística, que os docentes e preceptores médicos que afirmaram buscar orientar os seus alunos sobre empatia apresentaram maiores escores nas dimensões FS $(0,0341)$, CE $(0,0398)$, TP $(0,0464)$, bem como na média geral

\begin{tabular}{|ccc|} 
Tabela 2 & \\
Aspectos pessoais quanto à empatia dos 101 professores e preceptores \\
médicos de um curso de Medicina, Goiânia, Goiás, Brasil, 2018 \\
\hline \multicolumn{2}{|c|}{ Variáveis $(\mathbf{n}=\mathbf{1 0 1})$} & $\mathbf{f}(\%)$ \\
\hline Foi orientado sobre empatia na graduação & & \\
Sim & 59 & 58,4 \\
Não & 42 & 41,6
\end{tabular}

Orienta seus alunos sobre empatia

$\begin{array}{lll}\text { Sim } & 80 & 79,2 \\ \text { Não } & 21 & 20,8\end{array}$

Considera-se empático

$\begin{array}{ccc}\text { Sim } & 93 & 92,1 \\ \text { Não } & 8 & 7,9\end{array}$

A teoria é suficiente para ensinar empatia

$\begin{array}{ccc}\text { Sim } & 7 & 6,9 \\ \text { Não } & 94 & 93,1\end{array}$

Prática da empatia tem impacto positivo

$\begin{array}{ccc}\text { Sim } & 100 & 99,0 \\ \text { Não } & 1 & 1,0\end{array}$

Empatia pode ser desenvolvida no acadêmico

$\begin{array}{ccc}\text { Sim } & 99 & 98,0 \\ \text { Não } & 2 & 2,0\end{array}$

Satisfeito com suas atitudes com professor

$\begin{array}{lll}\text { Sim } & 87 & 86,1 \\ \text { Não } & 14 & 13,9\end{array}$

Fonte: Elaborada pelos autores. 
$(0,0442)$, sobrepondo-se àqueles que não orientam. Observou-se ainda que aqueles que afirmaram que são pessoas empáticas apresentaram maiores escores nas dimensões FS $(0,0327)$, CE $(0,0061)$, TP $(0,0008)$ e média geral $(0,0067)$. Outro aspecto a ser ressaltado é o fato de que os participantes que se autoanalisaram afirmando que estão satisfeitos com suas atitudes no exercício da docência obtiveram maior escore na dimensão TP $(0,0289)$ (Tabela 4$)$.

\section{DISCUSSÃO}

A empatia reflete uma habilidade inata de perceber as emoções de outra pessoa e ser sensível a elas, com motivação para se preocupar com o bem-estar desse outro. Reações empáticas emergem desde a infância e não ocorrem de forma inconsciente, automática; pelo contrário, são moduladas e altamente influenciadas por fatores contextuais interpessoais, impactando o comportamento e a cognição ${ }^{13}$.

\section{Tabela 3}

Comparação dos escores de empatia medidos pela EMRI com o perfil sociodemográfico dos 101 professores e preceptores médicos de um curso de Medicina, Goiânia, Goiás, Brasil, 2018

\begin{tabular}{|c|c|c|c|c|c|c|c|c|c|c|c|c|c|c|c|}
\hline \multirow{2}{*}{ Variáveis $(n=101)$} & \multicolumn{2}{|c|}{ FS } & \multirow{2}{*}{ p-valor } & \multicolumn{2}{|c|}{$\mathrm{CE}$} & \multirow{2}{*}{ p-valor } & \multicolumn{2}{|c|}{ AP } & \multirow{2}{*}{ p-valor } & \multicolumn{2}{|c|}{ TP } & \multirow{2}{*}{ p-valor } & \multicolumn{2}{|c|}{ Geral } & \multirow{2}{*}{ p-valor } \\
\hline & Média & DP & & Média & DP & & Média & DP & & Média & DP & & Média & DP & \\
\hline \multicolumn{16}{|l|}{ Idade } \\
\hline Até 45 anos & 22,1 & 6,1 & & 29,9 & 4,6 & & 14,3 & 5,0 & & 26,0 & 2,7 & & 92,3 & 14,0 & \\
\hline $\begin{array}{l}\text { Acima de } 45 \\
\text { anos }\end{array}$ & 21,8 & 5,1 & 0,6805 & 30,2 & 3,2 & 0,5368 & 14,3 & 5,3 & 0,9912 & 25,9 & 2,9 & 0,8513 & 92,1 & 11,6 & 0,7771 \\
\hline \multicolumn{16}{|l|}{ Sexo } \\
\hline Feminino & 23,0 & 4,7 & & 31,1 & 3,1 & & 15,7 & 4,6 & & 26,3 & 2,5 & & 96,1 & 10,3 & \\
\hline Masculino & 20,9 & 6,1 & 0,0468 & 29,1 & 4,5 & 0,0219 & 13,4 & 5,2 & 0,0230 & 25,5 & 2,9 & 0,1336 & 88,7 & 13,6 & 0,0057 \\
\hline \multicolumn{16}{|l|}{ Estado civil } \\
\hline Solteiro & 20,8 & 8,4 & & 30,3 & 5,1 & & 15,8 & 6,2 & & 24,8 & 3,9 & & 91,5 & 20,8 & \\
\hline Casado & 21,6 & 5,3 & & 29,9 & 4,0 & & 14,1 & 5,2 & & 25,9 & 2,6 & & 91,4 & 12,2 & \\
\hline Divorciado & 24,4 & 4,3 & 0,2234 & 30,5 & 3,8 & 0,7748 & 15,7 & 2,7 & 0,3943 & 26,6 & 2,7 & 0,5069 & 97,2 & 8,9 & 0,3093 \\
\hline \multicolumn{16}{|l|}{ Religião } \\
\hline Sim & 21,9 & 5,5 & & 30,1 & 4,0 & & 14,7 & 5,0 & & 25,9 & 2,8 & & 92,6 & 12,6 & \\
\hline Não & 21,0 & 6,2 & 0,8462 & 28,2 & 4,9 & 0,3579 & 9,3 & 2,7 & 0,0074 & 25,8 & 2,6 & 0,8914 & 84,3 & 11,9 & 0,1296 \\
\hline \multicolumn{16}{|l|}{$\begin{array}{l}\text { Envolvimento } \\
\text { religioso }\end{array}$} \\
\hline Fraco & 21,7 & 6,4 & & 29,5 & 4,8 & & 14,5 & 4,6 & & 25,1 & 2,8 & & 90,7 & 13,0 & \\
\hline Moderado & 21,9 & 5,6 & & 29,9 & 4,0 & & 15,3 & 5,5 & & 25,7 & 2,9 & & 92,8 & 13,5 & \\
\hline Forte & 22,1 & 5,1 & 0,9776 & 30,7 & 3,6 & 0,6439 & 13,8 & 4,2 & 0,5653 & 26,5 & 2,5 & 0,2575 & 93,1 & 11,2 & 0,8390 \\
\hline
\end{tabular}

Pratica atividade

física

\begin{tabular}{|c|c|c|c|c|c|c|c|c|c|c|c|c|c|c|}
\hline \multirow{2}{*}{$\begin{array}{l}\text { Sim } \\
\text { Não }\end{array}$} & 21,9 & 5,4 & & 30,0 & 4,1 & & 14,5 & 5,1 & & 25,9 & 2,4 & & 92,4 & 12,5 \\
\hline & 21,7 & 6,1 & 0,8097 & 29,8 & 4,0 & 0,7064 & 14,1 & 5,0 & 0,7296 & 25,7 & 3,7 & 0,7296 & 91,3 & 13,3 \\
\hline
\end{tabular}

Tempo de

graduação em

Medicina

Menos de dez anos

$20,3 \quad 6,9$

$29,6 \quad 5,3$

$13,3 \quad 4,8$

$25,2 \quad 3,9$

88,3

17,6

Mais de dez anos

$22,1 \quad 5,4 \quad 0,2254$

$30,0 \quad 3,9 \quad 0,7409$

$14,6 \quad 5,1 \quad 0,2867$

$26,0 \quad 2,6 \quad 0,7251$

92,6

$11,9 \quad 0,3316$

Tempo de

docência em

Medicina

Menos de dez anos

$21,9 \quad 5,9$

Mais de dez anos

$21,8 \quad 5,2 \quad 0,8515$

$\begin{array}{lrr}29,6 & 4,5 & \\ 30,4 & 3,4 & 0,7906\end{array}$

$14,2 \quad 4,9$

$14,7 \quad 5,2 \quad 0,6049$

25,7

2,7

91,5

13,7

Fonte: Elaborada pelos autores. 


\begin{tabular}{|c|c|c|c|c|c|c|c|c|c|c|c|c|c|c|c|}
\hline \multirow{2}{*}{ Variáveis $(n=101)$} & \multicolumn{2}{|c|}{ FS } & \multirow{2}{*}{ p-valor } & \multicolumn{2}{|c|}{$\mathrm{CE}$} & \multirow{2}{*}{ p-valor } & \multicolumn{2}{|c|}{ AP } & \multirow{2}{*}{ p-valor } & \multicolumn{2}{|c|}{ TP } & \multirow{2}{*}{ p-valor } & \multicolumn{2}{|c|}{ Geral } & \multirow{2}{*}{ p-valor } \\
\hline & Média & DP & & Média & DP & & Média & DP & & Média & DP & & Média & DP & \\
\hline \multicolumn{16}{|l|}{$\begin{array}{c}\text { Foi orientado } \\
\text { sobre empatia na } \\
\text { graduação }\end{array}$} \\
\hline Sim & 22,3 & 5,5 & & 30,1 & 3,9 & & 14,1 & 5,6 & & 25,8 & 2,8 & & 92,2 & 13,4 & \\
\hline Não & 21,3 & 5,7 & 0,3759 & 29,8 & 4,3 & 0,9232 & 14,9 & 4,2 & 0,3452 & 26,0 & 2,6 & 0,8068 & 91,9 & 11,8 & 0,8201 \\
\hline \multicolumn{16}{|l|}{$\begin{array}{l}\text { Orienta seus } \\
\text { alunos sobre } \\
\text { empatia }\end{array}$} \\
\hline Sim & 22,4 & 5,5 & & 30,4 & 3,7 & & 14,3 & 5,1 & & 26,1 & 2,7 & & 93,2 & 12,3 & \\
\hline Não & 20,0 & 5,6 & 0,0341 & 28,3 & 4,9 & 0,0398 & 14,8 & 4,7 & 0,6156 & 24,8 & 2,6 & 0,0464 & 87,9 & 13,4 & 0,0442 \\
\hline \multicolumn{16}{|l|}{$\begin{array}{c}\text { Considera-se } \\
\text { empático }\end{array}$} \\
\hline Sim & 22,2 & 5,3 & & 30,4 & 3,7 & & 14,5 & 5,1 & & 26,2 & 2,5 & & 93,3 & 11,8 & \\
\hline Não & 17,5 & 7,2 & 0,0327 & 25,4 & 4,8 & 0,0061 & 13,0 & 3,3 & 0,4813 & 22,3 & 2,8 & 0,0008 & 78,1 & 14,5 & 0,0067 \\
\hline \multicolumn{16}{|l|}{$\begin{array}{c}\text { A teoria é } \\
\text { suficiente para } \\
\text { ensinar empatia }\end{array}$} \\
\hline Sim & 19,7 & 4,2 & & 28,9 & 4,9 & & 13,6 & 4,7 & & 26,0 & 2,0 & & 88,1 & 11,6 & \\
\hline Não & 22,0 & 5,6 & 0,2878 & 30,1 & 4,0 & 0,4185 & 14,5 & 5,1 & 0,6883 & 25,9 & 2,8 & 0,9840 & 92,4 & 12,8 & 0,3562 \\
\hline \multicolumn{16}{|l|}{$\begin{array}{c}\text { Empatia pode ser } \\
\text { desenvolvida no } \\
\text { acadêmico }\end{array}$} \\
\hline Sim & 21,9 & 5,6 & & 29,9 & 4,1 & & 14,5 & 5,0 & & 25,8 & 2,8 & & 92,1 & 12,8 & \\
\hline Não & 21,5 & 0,7 & 0,9285 & 32,0 & 1,4 & 0,4755 & 10,5 & 3,5 & 0,2679 & 27,0 & 1,4 & 0,5563 & 91,0 & 4,2 & 0,9022 \\
\hline \multicolumn{16}{|l|}{$\begin{array}{c}\text { Está satisfeito com } \\
\text { suas atitudes como } \\
\text { professor }\end{array}$} \\
\hline Sim & 21,6 & 5,4 & & 30,1 & 4,0 & & 14,2 & 5,0 & & 26,1 & 2,6 & & 92,0 & 12,2 & \\
\hline Não & 23,2 & 6,6 & 0,3248 & 29,4 & 4,3 & 0,5912 & 15,6 & 5,1 & 0,3275 & 24,6 & 3,3 & 0,0289 & 92,9 & 15,7 & 0,8108 \\
\hline
\end{tabular}

Fonte: Elaborada pelos autores.

Os mecanismos de desenvolvimento da empatia são flexíveis e passíveis de intervenções que podem promover o "olhar para o outro", mesmo que esse outro seja um desconhecido. Dessa forma, a presente investigação dos níveis de empatia em professores e preceptores médicos de um curso de Medicina objetivou mensurar o nível dessa habilidade/ capacidade no mencionado universo, presumindo a importância da empatia na relação humana, em especial no âmbito da formação médica ${ }^{14}$.

A empatia se correlaciona positivamente com comportamentos pró-sociais e altruísticos, bem como com várias habilidades pessoais que conduzem à construção de relações humanas, incluindo socialização, simpatia, flexibilidade, tolerância, inteligência emocional, julgamento moral, senso de humor, conscientização, abertura a experiências, influência social positiva, conquista pessoal, trabalho em equipe e colaboração interprofissional ${ }^{14}$.

Os dados obtidos permitiram ponderar que o sexo feminino apresentou maiores níveis globais de empatia quando comparados aos do sexo masculino e também maiores níveis nas dimensões AP, CE e FS da EMRI. Tal fato se refere a uma maior propensão das mulheres para se sentirem desconfortáveis com o sofrimento do outro: há uma tendência a ajudar as pessoas que estão sofrendo e incorporar/sentir a perspectiva de outras pessoas que estão em sofrimento.

As mulheres, em comparação com a população geral e no meio profissional da saúde, frequentemente apresentam maiores escores que os homens em mensurações de níveis de empatia. Há explicações plausíveis para diferenças de gênero na empatia. Por exemplo, mulheres possuem uma maior capacidade de se relacionar socialmente do que os homens, o que se evidencia pelas observações de que elas frequentemente começam a mostrar sensibilidade aos estímulos sociais e emocionais mais cedo, e demonstram mais qualidades orientadas ao “cuidar" em idades mais precoces ${ }^{14}$. 
Embora o aprendizado social e os valores culturais tenham importante papel no comportamento social e na empatia, outros fatores, como a evolução histórica humana (por exemplo, divisão social do trabalho, investimento dos pais na educação dos filhos etc.), as disposições constitucionais e os fatores hormonais e biofisiológicos, também contribuem para as diferenças da empatia entre o feminino e o masculino $^{14}$.

Durante a formação médica, já se observa que as mulheres tendem a ter maiores níveis de empatia do que os homens. Diversas pesquisas recentes já foram publicadas confirmando tal realidade ${ }^{15-17}$. É de extrema relevância a evidência de que o sexo feminino possui maior compromisso com a perspectiva humanista e, consequentemente, é mais empático no encontro com seus pacientes ${ }^{15}$.

Ainda nos dias atuais, há resquícios no Brasil do estigma de que a mulher, em seu meio social, deve realizar tarefas domésticas e cuidar dos filhos e da família, ser o esteio e, por muitas vezes, o alento ${ }^{18}$. A partir dos avanços promovidos pelo movimento feminista, as mulheres passaram a participar ativamente dos cursos universitários e a produzir conteúdo científico, fatos que implementaram mudanças em nível mundial, perfazendo maior igualdade de gênero ${ }^{19}$.

A crescente feminização da medicina se deu a partir da década de 1970 e se tornou ponto essencial para que as mulheres pudessem exercer seus direitos na profissão médica ${ }^{19}$. Por trazer consigo tamanha experiência que lhe foi imputada pela sociedade, a busca da mulher pela medicina foi difícil. No entanto de alto valor para uma medicina mais humanizada. A relação médico-paciente mais empática, usualmente, tem sido estabelecida por médicas, por proporcionarem aos pacientes maior voz ativa e uma forma de colaboração mais democrática em seus atendimentos. Assim sendo, as profissionais médicas têm sido capazes de entender mais facilmente as características, peculiaridades e preferências individuais de seus pacientes ${ }^{17}$.

Os resultados do presente estudo indicam que as mulheres médicas contribuem, em seu universo, para o desenvolvimento da empatia nos estudantes de Medicina. Uma vez que a empatia constitui uma habilidade que pode ser estimulada e desenvolvida, o contato e a vivência dessas mulheres preceptoras/professoras com os acadêmicos de Medicina podem levar à formação de médicos mais empáticos e, consequentemente, a uma medicina mais humanizada.

No que tange à religião, identificou-se que os participantes que possuíam uma fé religiosa apresentaram maior escore na AP. A religião, muitas vezes, pode, por si só, influenciar o indivíduo na forma como ele vê o outro. A religiosidade se relaciona positivamente com o altruísmo, a visão holística, a empatia, bem como procura abordar temas que são relevantes na medicina, como vida, morte e espiritualidade ${ }^{20}$.

$\mathrm{O}$ presente estudo demonstrou que mais da metade dos participantes tiveram alguma orientação sobre empatia ao longo de sua formação, e a grande maioria acredita ser importante para a formação médica orientar seus alunos acerca da empatia. Ademais, os participantes que buscam orientar seus alunos sobre empatia apresentaram maior escore de empatia global e nas dimensões FS, CE e TP.

$\mathrm{O}$ acadêmico de Medicina tende a desenvolver certo cinismo à medida que progride na sua educação profissional, e a empatia tende a declinar ainda mais na formação especializada após a graduação ${ }^{14}$. Em contraponto a esse dado, um estudo que avaliou a empatia em estudantes de Medicina ingressantes e concluintes identificou que não havia diferença significativa entre os escores de empatia deles. Aliás, os dados desta pesquisa apontaram uma tendência dos concluintes em serem mais empáticos ${ }^{17}$. Esse desencontro de dados poderia ser mais bem estudado sob a ótica da medicina humanizada, em que a empatia ganha destaque, inclusive na formação acadêmica, o que poderia contribuir para o aumento dos níveis de empatia em formandos.

É de suma importância reforçar a empatia na educação médica e no cuidado ao paciente e aos seus familiares. Reforçar a empatia na formação médica deveria, aliás, ser considerado mandatório por professores e preceptores no meio acadêmico da saúde e instituições de saúde. A empatia, conforme já descrito, é um atributo flexível, que pode ser desenvolvido, mudado e reforçado inclusive no âmbito de programas e experiências educacionais ${ }^{21}$.

Deve haver um reforço constante do comportamento empático dos acadêmicos para que eles procurem agir com empatia na prática médica, e não apenas com seus pacientes, mas também com seus futuros alunos, com seus colegas de trabalho e ainda com as pessoas ao seu redor. Um docente que não é empático com seus acadêmicos, por exemplo, dificilmente consegue desenvolver empatia com outras pessoas ao seu redor, incluindo seus pacientes. Como a empatia não é compartimentada, a forma mais eficaz de promovê-la e incentivá-la é praticando-a ${ }^{21}$.

É de fundamental importância que professores e preceptores médicos reconheçam que a empatia pode ser aprendida pelos estudantes durante a formação médica. Além disso, devem reconhecer que essa habilidade é imprescindível na relação médico-paciente ${ }^{22}$.

Assim, a comunicação empática é necessária e essencial na formação médica e deve ser ensinada/reforçada no meio acadêmico. E esse aprendizado não é fácil, pois necessita de esforço e prática. Na relação médico-paciente empática, o paciente percebe o médico como alguém que quer ajudá-lo, como alguém que vai lhe oferecer suporte social com benefícios clínicos, o que inevitavelmente contribui para melhores resultados terapêuticos ${ }^{14}$.

Identificou-se que os professores e preceptores médicos que se consideravam mais empáticos, de fato, apresentaram maior nível de empatia global e nas dimensões FS, CE e TP. Já os professores e preceptores médicos que afirmaram estar satisfeitos com suas atitudes como docentes apresentaram maior escore na dimensão TP.

Os docentes, desde a formação básica, são referenciais e possuem papel de destaque no ambiente social. Interferem diretamente no comportamento daqueles que são seus alunos. Sendo assim, o professor deve se sentir comprometido com a formação ética e moral dos educandos, uma vez que é mencionada essa postura em documentos como as Diretrizes Curriculares Nacionais dos cursos superiores, para melhor consolidar os valores sociais ${ }^{23}$

Em um curso de Medicina, os acadêmicos possuem uma forte influência daqueles que os instruem, isto é, seus professores e preceptores, principalmente aqueles que são profissionais médicos. Comumente, pessoas que não possuem empatia atribuem isso ao fato de que não receberam empatia em sua formação e que, por esse motivo, não têm a obrigação de repassar o que não lhes foi diretamente ensinado. As situações vivenciadas no ambiente universitário podem influenciar a visão e o posicionamento do acadêmico, quando este precisar tomar uma conduta diante da queixa de um paciente. A empatia normalmente

REVISTA BRASILEIRA DE EDUCAÇÃO MÉDICA

7 (1) : e043; 2020 
é estimulada nos casos em que os preceptores observam as características e respeitam a individualidade de seus pacientes ${ }^{17}$.

Como determinantes na formação acadêmica, os professores devem se conscientizar de que o seu comportamento e sua empatia estão sendo observados e replicados por seus alunos. O chamado bom comportamento deve, por si só, ser capaz de captar o desejo dos alunos de se tornarem pessoas melhores, com maior predisposição a se tornarem médicos mais empáticos no futuro ${ }^{23}$.

É fato que, no contexto da prática médica, a conexão entre empatia e resultados clínicos positivos baseia-se nos seguintes argumentos: quando uma relação empática é desenvolvida, uma relação de confiança também será obtida, e essa confiança irá minorar os obstáculos da relação médicopaciente, que conduzirá à maior adesão do paciente e, consequentemente, obter-se-á um resultado clínico mais acurado ${ }^{14}$.

\section{CONCLUSÃO}

Os fatores sociodemográficos que interferem positivamente na empatia dos professores e preceptores médicos investigados foram o gênero feminino e o fato de terem uma religião. Os aspectos pessoais que obtiveram maiores escores de empatia foram: os docentes e preceptores médicos que afirmaram buscar orientar os seus alunos sobre empatia, aqueles que afirmaram que são pessoas empáticas e os que estavam satisfeitos com suas atitudes no exercício da docência.

É notório o papel dos docentes e preceptores médicos no estímulo ao desenvolvimento da empatia nos acadêmicos de Medicina, cujo papel desenvolvido na formação e comportamento interferem diretamente na conduta dos futuros médicos. Sendo assim, ações importantes nos cursos de Medicina devem ser implementadas com vistas a desenvolver cada vez mais a empatia em seus professores e preceptores médicos, cuja prática terá implicações diretas no estudante de Medicina.

Espera-se, portanto, que esta pesquisa contribua positivamente para o saber e pragmatismo dos profissionais médicos que se propõem a ser professores e preceptores de um curso de Medicina e que a prática fiel e vigilante da empatia se torne companheira dos acadêmicos, professores e preceptores médicos alcançados por este estudo. -

\section{REFERÊNCIAS}

1. Pontes L. A empatia no processo de ensinar e aprender: um estudo com professores do curso de graduação em Enfermagem de uma universidade pública. Cuiabá. Tese [Doutorado em Educação] Universidade Federal de Mato Grosso; 2013.

2. Delgado-Bolton R, San-Martín M, Alcorta-Garza A, Vivanco L. Empatía médica en médicos que realizan el programa de formación médica especializada. Estudio comparativo intercultural en España. Aten. prim. 2016;48(9):565-71.

3. Löffler-Stastka H, Datz F, Parth K, Preusche I, Bukowski X, Seidman C. Empathy in psychoanalysis and medical education - what can we learn from each other? BMC med. educ. 2017;17(1):1-6.

4. Braga-Simões J, Costa PS, Yaphe J. Placebo prescription and empathy of the physician: a cross-sectional study. Eur J Gen Pract. 2017;23(1):98-104.

5. Formiga N, Rocha M, Souza M, Stevam I, Fleury L. Confiabilidade da Escala Multidimensional de Reatividade Interpessoal (EMRI) no contexto brasileiro. Revista de Psicología GEPU. 2014;5(2):32-43.

6. Brasil. Ministério da Educação. Resolução no 3, de 20 de junho de 2014. Institui Diretrizes Curriculares Nacionais do Curso de Graduação em Medicina e dá outras providências. Brasília; 2014.

7. Batista NA, Silva SHS. O professor de Medicina: conhecimento, experiência e formação. São Paulo: Loyola; 1998.

8. Costa FD da, Azevedo RCS de. Empatia, relação médico-paciente e formação em medicina: um olhar qualitativo. Rev. bras. educ. méd. 2010;34(2):261-9.

9. Bastos JLD, Duquia RP. Um dos delineamentos mais empregados em epidemiologia: estudo transversal. Sci. med. 2007;17(4):229-32.

10. Sitta E, Arakawa A, Caldana M, Peres S. Contribution of crosssection studies in the language area with focus on aphasia. Rev. CEFAC 2010;12(6):1059-66.

11. Sampaio LR, Menezes IG. Estudos sobre a dimensionalidade da empatia: tradução e adaptação do Interpersonal Reactivity Index (IRI). Psico (Porto Alegre) 2011;42(2):67-76.

12. Formiga NS, Rocha MCO, Reis DA dos, Costa SM da S, Leime J. Fidedignidade da estrutura fatorial da Escala Multidimensional de Reatividade Interpessoal (EMRI). Estud. Interdiscip. Psicol. 2013;4(1):64-79.

13. Decety J. The neural pathways, development and functions of empathy. Curr Opin Behav Sci. 2015;3:1-6.

14. Hojat M. Empathy in health professions education and patient care. Switzerland: Springer; 2016.

15. Anaya MVM, Amador LRT, Martínez FG. Factores relacionados con la empatía en estudiantes de medicina de la Universidad de Cartagena. Rev. clín. med. fam. 2015;8(3):185-92.

16. Esquerda $M$, Yuguero O, Viñas J, Pifarré J. La empatía médica, ¿nace o se hace? evolución de la empatía en estudiantes de medicina. Aten. prim. 2016;48(1):8-14.

17. Nascimento HCF, Ferreira Júnior WA, Silva AMTC, Carvalho IGM, Bastos GCFC, Almeida RJ. Análise dos níveis de empatia de estudantes de medicina. Rev. bras. educ. méd. 2018;42(1):150-8.

18. Lombardi MR. Mulheres em carreiras de prestígio: conquistas e desafios à feminização. Cad. pesqui. 2017;47(163):10-4.

19. Minella LS. Medicina e feminização em universidades brasileiras: $o$ gênero nas interseções. Rev Estud Fem. 2017;25(3):1111-28.

20. Huarcaya-Victoria J, Rivera-Encinas MT. Evaluation of medical empathy in students of a private university in Peru. Educ. med. 2018;20(supl 2):100-7. doi: 10.1016/j.edumed.2018.05.008.

21. San-Martín M, Roig-Carrera H, Villalonga-Vadell RM, BenitoSevillano C, Torres-Salinas M, Claret-Teruel G, et al. Empatía, habilidades de colaboración interprofesional y aprendizaje médico permanente en residentes españoles y latinoamericanos que inician los programas de formación médica especializada en España. Resultados preliminares. Aten. prim. 2017;49(1):6-12.

22. Archer E, Turner R. Empathy: an essential tool in any doctor's skillset. S. Afr. med. J. 2018;109(1):11-2.

23. Macedo EP, Pessoa P dos S, Domingues VB. A relação professor-aluno e a ética no ensino superior. Rev Educ ANEC. 2018;42(155):26-40. 


\section{CONTRIBUIÇÃO DOS AUTORES}

Geórgia Ferreira Nunes, Thays Ferreira Guimarães e Rogério José de Almeida participaram da concepção e do planejamento do projeto de pesquisa, da coleta, análise e interpretação dos dados, da redação e revisão final. Júlia da Paixão Oliveira Mello e Pargeon, Gabriela Cunha Fialho Cantarelli Bastos e Antonio Márcio Teodoro Cordeiro Silva participaram da análise e interpretação dos dados, redação e revisão final.

\section{CONFLITO DE INTERESSES}

Os autores declaram não haver conflito de interesses.

\section{ENDEREÇO PARA CORRESPONDÊNCIA}

Rogério José de Almeida. Avenida Universitária, 1440, Área 4, Bloco K, Setor Universitário, Goiânia, GO, Brasil. CEP: 74605-010.

E-mail: rogerioufg@hotmail.com 